\title{
A INICIAÇÃO DA ESCRITA ACADÊMICA EM UM CURSO DE LICENCIATURA EM CIÊNCIAS BIOLÓGICAS*
}

\section{A FIRST APROACH TO ACADEMIC WRITING IN A TEACHING DEGREE IN BIOLOGICAL SCIENCES}

\author{
Vera Lucia Bonfim Tiburzio* \\ Marinalva Vieira Barbosa ${ }^{\star \star \star}$
}

\begin{abstract}
RESUMO: Este artigo apresenta uma análise do percurso de iniciação à escrita de projeto de pesquisa por alunos iniciantes do Curso de Licenciatura em Ciências Biológicas de uma universidade pública. O foco das análises não recaí sobre os procedimentos metodológicos atinentes ao ensinar a escrever na universidade, mas sobre a escrita e sobre o modo como o aluno se relaciona com a escrita acadêmica ao iniciar a graduação. Os dados resultaram de um trabalho de ensino da escrita, desenvolvido em um semestre, ancorado na concepção de que o aprendizado da escrita envolve escrever e reescrever, em que 05 grupos de alunos produziram coletivamente projetos de pesquisa na disciplina "Estudos e Desenvolvimento de Projetos (EDP I). Versões das introduções e desenvolvimento da metodologia de quatro destes projetos são analisadas, focando questões relacionadas à escrita do desenvolvimento do tema, uso de senso comum como argumentos, desenvolvimento da clareza e coerência textual e a relação com a palavra do outro, especialmente o plágio. Os resultados mostram que os alunos apresentam pouca familiaridade com as formas de escrita típica dos gêneros acadêmicos, como projetos e artigos, e sobre o que é fazer uma pesquisa; principalmente, apresentam falta de familiaridade com os percursos necessários à construção de um gênero acadêmico como o projeto de pesquisa. No entanto, com as oportunidades promovidas pela disciplina, foi possível perceber o progresso de alguns grupos que passaram a apresentar fundamentação teórica mais consistente, no que diz respeito a qualidade e relevância das fontes citadas e melhora quanto a clareza e organização lógica da redação do projeto final. O pensar e produzir a escrita orquestrada a partir da reescrita foi uma oportunidade de auto diagnóstico dos alunos sobre as potencialidades e fragilidades nesse campo de escrita.
\end{abstract}

Palavras-chave: Escrita; Prática de ensino; Ensino superior.

\footnotetext{
Neste artigo apresentamos resultados parciais de uma das várias etapas de desenvolvimento do projeto "Leitura e escrita no Brasil, Honduras, Angola e Chile: formação na universidade contemporânea e (re)produção de conhecimento" (CNPq 427044/2018-9). O objetivo desse projeto maior é analisar a leitura e a escrita acadêmicas de alunos de diferentes áreas, inseridos em contextos culturais diversos, com vistas a verificar traços definidores dessas produções e problematizar a universidade contemporânea, tanto como espaço de formação de sujeito produtor de conhecimento, quanto, consequentemente, como espaço de produção de conhecimento.

* Doutorado em Biologia Funcional e Molecular pela Universidade Estadual de Campinas (UNICAMP). Docente da Universidade Federal do Triângulo Mineiro (UFTM). Contato: profvera2009@gmail.com

*** Doutorado em Linguística pela Universidade Estadual de Campinas (UNICAMP). Docente da Universidade Federal do Triângulo Mineiro (UFTM). Contato: marinalva.barbosa@uftm.edu.br
} 
ABSTRACT: This article presents an analysis of a academic route in the beginning in how to make a Research Project in Writing habilities by students initial levels in Biological Sciences Degree Course at a Brazilian Public University. The focus of the analysis is not on the methodological procedures pertaining to teaching writing at the university, but on writing and the way the student relates to academic writing when starting an undergraduate course. The data resulted from a work of teaching writing, developed in one semester level, anchored in the conception that learning to write involves writing and rewriting, in which 05 groups of students collectively produced research projects in the discipline "Studies and Project Development" (EDP I). Versions of the introductions and methodology development for four of these projects are analyzed in this article, focusing on issues related to the writing of the theme development, use of common sense as arguments, development of clarity and textual coherence and the relationship with the other's word, especially the plagiarism. The results show that students have no knowhow with the forms of writing typical of academic genres, such as projects and articles, and about what it is to do a research; mainly, they lack no absolute knowhow with the paths necessary to build an academic genre such as the research project. However, with the opportunities promoted by the discipline, it was possible to notice the progress of some groups that started to present more consistent theoretical foundation, regarding the quality and relevance of the sources cited and improvement as to the clarity and logical organization of the final project writing. Thinking and producing orchestrated writing based on rewriting was an opportunity for students to self-diagnose about the strengths and weaknesses in this writing field.

Keywords: Writing; Teaching practice; University education; High Education.

\section{INTRODUÇÃO}

De acordo com Moysés, Geraldi e Collares (2002), a universidade é reconhecida como espaço privilegiado de produção de conhecimento. Também é nela que se dá o acesso, o aprendizado de conhecimentos produzidos por gerações anteriores. $\mathrm{O}$ acesso ao conhecimento existente e a produção de novos passa pela escrita, pelo saber ler o texto do outro e pelo saber a escrever o próprio texto. Dito de outro modo, a escrita tem papel de destaque como lugar de registro da apropriação e interpretação da herança intelectual precedente e, principalmente, daquilo que pode acrescentar a essa herança.

Nesse sentido, no ambiente acadêmico, é importante que os estudantes, no início de sua jornada de formação, tenham acesso à forma de conhecimento proveniente da pesquisa acadêmica, o que também implica apresentar as formas de escrita normalmente utilizadas na produção desse conhecimento. Vários estudos têm mostrado que o aprendizado da escrita na universidade é determinante para o desenvolvimento e, principalmente, para a qualidade da formação inicial de 
licenciandos (BERNHEIM E CHAUÍ 2008; BARZOTTO E BARBOSA 2014; E BARZOTTO 2016).

Em princípio, alunos de ensino fundamental e, principalmente, de ensino médio, deveriam ter contato com os códigos, símbolos, nomenclaturas, jargões e gêneros textuais típicos das Ciências Naturais, bem como com os métodos de investigação e análise usados por estas Ciências. A Base Curricular Nacional Comum, por exemplo, pontua que:

As análises, investigações, comparações e avaliações contempladas nas competências e habilidades da área [de Ciências Naturais] podem ser desencadeadoras de atividades envolvendo procedimentos de investigação. Propõe-se que os estudantes do Ensino Médio ampliem tais procedimentos, introduzidos no Ensino Fundamental, explorando, sobretudo, experimentações e análises qualitativas e quantitativas de situações-problema.

Diante da diversidade dos usos e da divulgação do conhecimento científico e tecnológico na sociedade contemporânea, torna-se fundamental a apropriação, por parte dos estudantes, de linguagens específicas da área das Ciências da Natureza e suas Tecnologias. Aprender tais linguagens, por meio de seus códigos, símbolos, nomenclaturas e gêneros textuais, é parte do processo de letramento científico necessário a todo cidadão.

O Ensino Médio deve, portanto, promover a compreensão e a apropriação desse modo de "se expressar" próprio das Ciências da Natureza pelos estudantes. (BRASIL, 2017)

Na prática, no entanto, o ensino de Ciências Naturais na educação básica em geral ainda é focado na transmissão de "fatos científicos" e na centralidade do professor como fonte da informação (AMBROSETTI et al, 2015; BEZERRA, 2019). Desta forma, os alunos desta etapa têm poucas oportunidades de adquirirem uma melhor compreensão de métodos e da lógica subjacentes a estas ciências e de terem contato direto com as fontes primárias de divulgação científica. Não é de se estranhar, portanto, que ao ingressarem em um curso superior, estes alunos apresentem pouca familiaridade com estes métodos, lógicas e fontes bibliográficas, como foi percebido neste trabalho.

A escrita na universidade, de modo geral, tem como base a concepção de que o conhecimento precisa ser apresentado, interpretado com objetividade, superando o senso comum e o imediatismo opinativo de maneira a buscar expedientes de universalização. "A concepção ainda dominante nas universidades 
enxerga o conhecimento como um objeto a ser desvelado, externo ao sujeito que busca conhecer e, portanto, dele independente." Para os autores, cria-se a ideia para as gerações em formação de que se trata de algo que circula entre os estudantes de forma autônoma e, principalmente, é forte a ideia de que pode ser apresentado, transmitido para o outro de forma inalterada (MOYSÈS, GERALDI, COLLARES, 2002, p. 93).

Essas concepções impactam no modo de conceber, relacionar e produzir a escrita acadêmica, uma vez que as regras de enunciação propostas por essa escrita trazem a exigência de que essa linguagem apareça de maneira impessoal, ou seja, exige-se a produção de uma escrita afastada do sujeito da linguagem, como se o texto em questão pudesse se elevar para além do mundo, para além dos possíveis erros e enganos pertinentes a particularidade do sujeito (PEREIRA, 2013). Como relata Foucault: "A linguagem científica é o dispositivo que permite o controle e estabelecimento de um conjunto de regras segundo as quais se distingue 0 verdadeiro do falso" (FOUCAULT, 1993a, p. 13).

Diante do exposto, neste artigo o objetivo principal é analisar a construção da escrita acadêmica de alunos de uma disciplina de primeiro período do curso de Licenciatura em Ciências Biológicas, da Universidade Federal do Triângulo Mineiro, intitulada Estudos e Desenvolvimento de Projetos I (EDP I). O objetivo da disciplina foi introduzir os alunos à concepção, redação e apresentação de um projeto de pesquisa na área educacional. Escrever e desenvolver projetos de pesquisa é uma prática comum às diversas áreas do conhecimento técnico, científico e acadêmico e, por isso, alguns conteúdos essenciais foram abordados em EDP I, como o uso da bibliografia para o embasamento do projeto, as formas adequadas de citação de outros autores (e, por consequência, o uso dos mecanismos de busca de informações) e as estratégias usuais para coleta e análise de dados.

No decorrer da realização da EDP I foram produzidos cinco projetos, quatro, dos quais serão analisados neste artigo. A redação da introdução e da metodologia foram as partes selecionadas para análise considerando o seguinte: para redigir a introdução, além de necessidade de saber o que iriam pesquisar (os objetivos), os alunos precisariam também ter um problema de pesquisa. Já para escrever a metodologia, precisariam ter em mente como fariam a pesquisa. Ou seja, os três 
pontos fundamentais de um projeto precisariam aparecer nessas duas etapas de escrita. Nesse sentido, acreditamos que a escolha deste recorte para análise proporcionaria a docente recolher informações sobre a maturidade acadêmica dos alunos na escrita e o retorno deles as atividades solicitadas em sala de aula.

\section{A DISCIPLINA EPD I: DESCRIÇÃO DO CONTEXTO DE PESQUISA.}

Como estratégia para a realização da EDP I, a disciplina foi dividida em dois momentos, sendo o primeiro uma sequência de aulas expositivas dialogadas, com duração de quatro semanas. Na primeira semana, foram apresentadas e discutidas concepções sobre o método na pesquisa acadêmica, na segunda semana as discussões se basearam sobre o que é pesquisa quantitativa, qualitativa e mista. $\mathrm{Na}$ terceira semana, foi apresentado e discutido o que é uma pesquisa bibliográfica e em seguida os discentes participaram de uma palestra com a bibliotecária da universidade que apresentou as normas de citações e referências. Para encerrar este primeiro momento da disciplina, foi ensinado como se estruturar um projeto de pesquisa e discutidos os elementos básicos para esta construção.

No segundo momento da disciplina, foram realizadas rodas de discussão, tendo como base a leitura das referências bibliográficas da disciplina. As rodas de discussão tinham como propósito aproximar os discentes da literatura científica e, por isso, inicialmente foram apresentadas as referências bibliográficas da disciplina e realizadas discussões das leituras indicadas. Após as rodas, foi a vez das oficinas de escrita para discussões sobre os temas dos projetos e, posteriormente, também para realização das correções. As discussões propostas nas rodas subsidiariam as oficinas.

As oficinas foram realizadas no laboratório de informática da universidade para que os discentes tivessem possibilidade de iniciar a escrita já com a presença da docente responsável pela disciplina. As oficinas foram organizadas por temáticas e realizadas na seguinte sequência: oficina sobre temas e objetivos; sobre metodologia e em seguida sobre introdução e justificativa. Na primeira oficina, os grupos foram orientados a trazer o tema escolhido e a partir disso foram feitas discussões para a escrita dos objetivos dos projetos. Questões como a diferença 
entre objetivo geral e específico, a escolha de verbos para iniciar os objetivos, distinguindo os que são objetivos exploratórios, descritivos e explicativos, foram abordados nesta primeira oficina. A oficina seguinte abordou a escrita da metodologia e justificativa; nesta, os discentes tinham que definir os passos a serem seguidos para se alcançar os objetivos propostos. O "como fazer" a pesquisa, o tempo de execução e os instrumentos de coleta e análise, principalmente o questionário e entrevista, foram temas para as discussões nestas oficinas.

Para a escrita da introdução dos projetos, a turma foi orientada sobre 0 levantamento bibliográfico e a importância de se operacionalizar a pesquisa ao longo de toda a disciplina. Para tanto, os alunos precisariam ter dimensão do problema de pesquisa, da base teórica de fundamentação do problema e para análise dos resultados pretendidos com a pesquisa.

O trabalho foi realizado ao longo de onze semanas no primeiro semestre de 2018. Cursaram a disciplina 25 alunos, divididos em cinco grupos, cada um dos quais responsável por um projeto. Os grupos trabalharam coletiva e semanalmente sob a orientação da docente responsável pela EDP I. Os grupos foram orientados a selecionar temas para seus projetos em diferentes áreas, mas envolvendo aspectos biológicos, sociais e, principalmente, educacionais; e a buscarem articular os projetos com outras unidades temáticas do período curricular em que se encontravam.

A produção da metodologia dos projetos é o momento em que os iniciantes no universo da pesquisa se vêm diante da necessidade de pensar passos, formas de realização, caminhos que serão percorridos. O método de pesquisa cientifica nada mais é do que o estabelecimento de pontos de partidas e de chegada. Segundo Bunge, "é um procedimento regular, explícito e passível de ser repetido para se conseguir-se alguma coisa, seja material ou conceitual" (BUNGE, 1980, p. 19). Foi solicitado aos grupos que, nos projetos, apresentassem o tempo previsto de execução do trabalho e os instrumentos utilizados para a coleta e análise de dados, sendo que métodos baseados em entrevistas e questionários foram inicialmente apresentados pela docente e discutidos em sala.

Assim, em relação à metodologia de ensino adotada no decorrer da EDP 1, a escrita das partes do projeto, conforme descrita nos parágrafos anteriores, envolveu 
três dimensões de aprendizado: a teórica, a prática e a temporal. A dimensão teórica foi organizada a partir da pesquisa bibliográfica realizada para a escrita do projeto e discussão dos seus resultados. Já a dimensão prática foi construída a partir das dificuldades experimentadas pelos alunos e do trabalho de revisão das versões do projeto em desenvolvimento (sete versões foram apresentadas por cada equipe até a entrega do projeto final). Por fim, a dimensão temporal fez com que os alunos compreendessem a necessidade de se estabelecer relações entre o tempo necessário para alcançar os objetivos propostos, o cronograma do projeto de pesquisa, e o tempo de realização da disciplina.

A avaliação na disciplina foi feita a partir de três conjuntos de parâmetros: a participação dos alunos nas oficinas de redação, nas rodas de discussão, que tiveram como base o resultado das leituras das referências bibliográficas da disciplina; a apresentação semanal dos textos em construção e a versão final escrita do projeto.

Neste artigo, foi analisada a evolução da escrita da introdução e da metodologia dos projetos até suas formas finais a partir de versões entregues semanalmente pelos cinco grupos de alunos que participaram da disciplina. Ao longo da disciplina foram produzidos 5 projetos distintos (um por grupo de alunos), sendo que, para cada um deles, foram redigidas e corrigidas sete versões. Neste artigo, serão analisados quatro destes projetos. A escolha destes quatro teve como critério o fato dos grupos correspondentes terem respondido a todas as intervenções semanais propostas para a organização e/ou reorganização da escrita, ou seja, com estes quatro não houve quebra de ritmo de trabalho o que possibilitou analisá-los ao longo de todo o semestre. Nesta análise serão apresentados recortes representativos dos processos através dos quais os textos de cada projeto evoluíram desde suas versões iniciais, por meio da constante re-análise destes proporcionada pelas discussões entre os membros do grupo e pelas intervenções da docente da disciplina. Nesta análise fica evidente também como o trabalho de produção (e re-produção) destes projetos permitiu aos alunos iniciarem uma familiarização com as linguagens, formas, métodos e lógicas próprias às Ciências Naturais. 
Conforme descrito acima, cada grupo de alunos entregava versões semanais dos projetos à docente, que por sua vez realizou intervenções principalmente por meio de questionamentos variados. Estes questionamentos buscavam principalmente estimular que os próprios alunos analisassem criticamente seus textos e, a partir desta análise, buscassem alterá-los de forma a construir um projeto que pudesse ser plenamente compreendido pelo leitor e, idealmente, implementado pelo grupo num segundo momento em outra disciplina chamada Estudos e Desenvolvimento de Projetos II (EDPII). Na disciplina EDP II os grupos implementam os projetos escrito na disciplina anterior, a EDP I, e produzem relatórios finais com a apresentação e a análise dos resultados obtidos. Desta maneira os grupos de alunos vivenciam na prática aquilo que planejaram e escreveram na disciplina de EDP I. Neste contexto, as intervenções docente ocorridas na EDP I buscaram estimular também que os grupos fossem capazes de avaliar a viabilidade dos projetos que tentavam construir, especialmente no que diz respeito a adequação dos recursos disponíveis, às capacidades que os próprios alunos, no tempo um semestre, teriam para implementá-lo na disciplina de (EDP II).

\section{ESCRITA E FORMAÇÃO INICIAL}

A discussão sobre o papel da escrita na formação inicial de professores em áreas diversas, que não a área de formação em Letras, ainda é restrita. A problematização sobre os processos de apropriação, desenvolvimento e organização da escrita como elemento necessário à constituição de um sujeito de conhecimento não se configura como questão pertinente a todas as áreas do conhecimento. Para além da área de Letras, o aprendizado da escrita fica bastante restrito ao ensino das normas de metodologias cientificas e do reconhecimento das formas de estruturação dos gêneros acadêmicos.

Atualmente, embora seja comum professores universitários apresentarem queixas sobre as dificuldades de escrita dos alunos de cursos de graduação, ainda persiste a compreensão de que esse aluno que entra na universidade deve apresentar domínio das habilidades de leitura e escrita; persiste, sobretudo, a compreensão de que ensinar a ler e escrever é uma tarefa da escola e não da 
universidade. Essa concepção é equivocada por duas razões: a primeira é que a escola não ensina a escrever e ler os gêneros acadêmicos; a segunda é que, no contexto atual, muitas vezes, o aluno que chega à universidade não apresenta domínio satisfatória da escrita e muito menos da escrita acadêmica.

As dificuldades de escrita, conforme será demonstrado nas análises, envolvem não só a inexperiência com os gêneros acadêmicos, mas também o não saber trabalhar com os recursos linguísticos e extralinguísticos. Germani (2017) apresenta a frágil capacidade dos alunos em produzirem textos com adequado domínio da norma culta, sentido e argumentação consistentes, conforme poderá ser visualizado nos textos que serão analisados neste artigo. Para esse autor,

Logo, vivemos uma realidade em que crianças avançam do Ensino Fundamental I com grandes dificuldades de leitura e escrita, jovens saem da escola sem ao menos saber escrever uma boa redação ou interpretar textos. A situação atingiu níveis extremos, em que alunos chegam às universidades analfabetos funcionais, ou seja, sabem ler, mas não conseguem interpretar o texto (GERMANI, 2017).

A interação com, na e por meio da língua é um aprendizado que lhes falta ou que não está construído de forma consistente. Então, o ensino dos gêneros acadêmicos, como o que ocorre nas disciplinas de metodologias cientificas, termina por não ser eficiente porque há uma dificuldade da parte do aluno para compreender qual trabalho deve desenvolver para organizar os enunciados de um determinado gênero. Nesse sentido, mostrar as dificuldades neste artigo não é o mesmo que ignorar os acertos dos alunos. Simplesmente, trata-se de mostrar que, no ensino da escrita na universidade, há que se compreender o ponto de partida do aluno e, principalmente, diagnosticar as dificuldades decorrentes desse ponto de partida para que, com isso, seja possível repensar as práticas de ensino da escrita, dos usos dos recursos linguísticos e extralinguísticos.

De acordo com Geraldi (1996), ensinar texto é o mesmo que ensinar a usar a língua a partir de um conjunto expressivo de outros elementos que ajudam a compor o texto. "Trata-se de pensar a relação de ensino como o lugar de práticas de linguagem e, a partir delas, com a capacidade de compreendê-las, não para descrevê-las como faz o gramático, mas para aumentar as possibilidades de uso exitoso da língua (GERALDI, 1996, p.71)." Por essa perspectiva, escrever é 
estabelecer relações entre recursos linguísticos e extralinguísticos orientado por um projeto de dizer. Logo, escrever exige estratégia para que o modo de organização do texto funcione para além da compreensão daquele que o produziu.

Nesse sentido, a primeira questão que se coloca como desafio para o aluno na universidade é a necessidade de produzir uma escrita orquestrada a partir da reescrita. A ideia ingênua de que saber escrever é resultado de inspiração e que, por isso, a produção fica pronta numa primeira escrita é a primeira barreira que precisa ser vencida. Escrita e reescrita formam um conhecimento que precisa ser construído na universidade, mas não pela via do dizer que é preciso fazer, mas sim pelo exercício, pelo trabalho com os recursos linguísticos e extralinguísticos. Isso envolve considerar que os recursos da língua precisam ser contextualizados em relação aos objetivos da escrita e que esta, para produzir sentidos, exige que quem escreve considere o objeto da escrita, os interlocutores e, principalmente, o que se pretende ao escrever. É desse aprendizado que trata a discussão feita neste artigo.

\section{RESULTADOS E DISCUSSÃO}

As primeiras versões dos projetos produzidos pelos alunos apresentaram várias características relacionadas à pouca familiaridade deles com os métodos de escrita, lógicas e fontes bibliográficas típicas das ciências naturais, em consonância com o que foi apresentado na introdução. Esta falta de familiaridade se manifestou principalmente na fundamentação teórica e bibliográfica (inclusive no que diz respeito à qualidade das fontes citadas) e na organização lógica dos argumentos e ideias dos projetos.

A análise desenvolvida aqui mostra que a falta de familiaridade com as formas usuais de escrita acadêmica afetou tanto a redação do projeto em si quanto a busca e leitura da bibliografia. Também tiveram dificuldades para produzir uma escrita que não fosse simples reprodução da própria oralidade. Outro aspecto que sobressaiu nos textos produzidos inicialmente foi a proximidade com a escrita usada nas redes sociais e outros meios eletrônicos, seja pelo uso de frases curtas, quase telegrafadas, pelo embasamento quase exclusivo destes num suposto "senso comum" ou pela pouca articulação (lógica e semântica) entre as partes do texto, 
observável até mesmo entre frases de um mesmo parágrafo ou orações de um mesmo período. Embora não seja objetivo deste artigo abordar as razões que dão sustentação a essas dificuldades, é inevitável que sejam levantados questionamentos sobre o quanto o ensino vivenciado por esses alunos no decorrer da educação básica foi efetivo ou não na apresentação das diferentes modalidades de escritas.

\section{A ESCOLHA DOS TEMAS}

Inicialmente, foi sugerido aos alunos que seus projetos focassem ações em educação, sem contudo que houvesse uma delimitação pela docente de um tema específico. Esta sugestão produziu uma primeira ruptura com as expectativas dos alunos, decorrente do fato de diferentes integrantes de cada grupo apresentarem sugestões de temas com as quais sentiam maior proximidade e segurança, mas que não necessariamente sensibilizavam os demais membros do grupo. Este embaraço para estabelecer diálogo em torno de um tema comum foi observada pela docente em vários momentos durante as orientações, nos quais os integrantes dos grupos frequentemente relatavam experiências e interesses pessoais com os temas que propunham. A predominância do interesse pessoal em detrimento do coletivo é compreensível, ao menos em parte, uma vez que os grupos eram formados por alunos ingressantes e, por isso, não compartilhavam ainda laços de proximidade nem tampouco experiências comuns.

Após discussões internas em cada grupo, os projetos foram definidos a partir de temas de relevância mais ampla e atual, a saber: "Os impactos ambientais gerados pelo descarte inadequado do óleo de cozinha", "A importância da coleta seletiva", "Medidas preventivas em casos de incêndios em instalações escolares", "Abordagem de práticas alimentares saudáveis e sustentáveis nas escolas de Uberaba" e "Universitários com dúvidas a respeito do curso que escolheram". Tais temas, conforme inicialmente propostos pelos grupos, tinham um caráter bastante aberto e complexo. Mesmo com a sugestão docente para que propusessem temas factíveis de serem realizados com tempo e recursos de que dispunham, observa-se que os alunos, de fato, não conseguiram se adequar a essa exigência. Quatro 
dentre os cinco temas empurravam os grupos para fora da universidade para que pudessem realizar suas pesquisas, ao mesmo tempo que a amplitude dos temas escolhidos exigia que os alunos apresentassem domínio teórico aprofundado. Por esta razão, teria sido importante para um melhor desenvolvimento da escrita e posterior execução dos projetos que tivessem proposto temas que pudessem ser desenvolvidos no âmbito local da Universidade, o que Ihes teria permitido melhores condições de lidarem com os possíveis problemas e dificuldades que poderiam surgir no momento das entrevistas e aplicações de questionários ao público-alvo. No embate entre viabilidade e aprendizado, a docente optou por permitir que os alunos levassem adiante a escolha dos temas dos projetos com considerável liberdade, partindo da concepção que a experiência futura de tentar implementar um projeto de menor viabilidade (na outra disciplina, intitulada EDP II) permitiria vivências e oportunidade de aprendizado muito maiores do que somente as adquiridas com a orientação da docente.

\section{A ESCRITA DA INTRODUÇÃO DOS PROJETOS}

A maioria dos grupos teve grandes dificuldades para escrever versões iniciais dos textos que realmente se configurassem como um projeto de pesquisa. No entanto, um deles desde o início conseguiu produzir uma proposta de trabalho viável e robusta, apesar de alguma confusão inicial sobre os sujeitos de pesquisa e os dados a serem avaliados. Um dos integrantes deste grupo já havia feito outra graduação e talvez tenha conseguido influenciar positivamente os demais discentes da equipe com a experiência vivenciada anteriormente. Não é possível neste contexto termos certeza dessa relação, mas esta existia e aqui se configura como uma hipótese.

Nesta etapa de escrita da introdução dos projetos a argumentação frequentemente era baseada em senso comum ou em opiniões próprias, similarmente ao relatado por Luna (1997) e a maioria dos textos também apresentou falta de clareza, coerência ou estruturação lógica.

Dos cinco projetos iniciais, dois apresentaram ainda plágios de trechos de outros autores sem as devidas citações. Esta questão do plágio foi discutida no 
início da disciplina, mas retomada em outros momentos conforme os grupos iam avançando na escrita.

\section{A FALTA DE ORGANIZAÇÃO LÓGICA}

Nas versões iniciais dos projetos, foi verificado o uso de informações atualizadas nas introduções, mas em geral estas não eram organizadas em uma sequência lógica. Com frequência, os textos adquiriam uma estrutura de "vai-e-vem", abordando problemas gerais, depois focando problemas pontuais e então retornando à questão geral; ou então eram simplesmente constituídos por coleções de frases "soltas", sem um encadeamento lógico. O trecho transcrito no quadro abaixo mostra um exemplo desta estrutura.

Texto dos alunos: "Este trabalho teve como temática a importância
da separação do lixo, da conscientização dos discentes e docentes e
da correta destinação do lixo que é produzido na UFTM diariamente.
Com o avanço da urbanização dos países em desenvolvimento, fato
no qual o Brasil se insere, é possível verificar o incessante aumento
da produção de lixo. Segundo Tinoco e Kraemer (2011, p. 89), a
gestão ambiental é "o sistema que inclui a estrutura organizacional,
atividades de planejamento, responsabilidades, práticas,
procedimentos, processos e recursos para desenvolver, implementar,
atingir, analisar criticamente e manter a política ambiental".
Intervenção do docente: "Há muitas boas informações nesta
introdução, mas infelizmente elas não foram organizadas numa
sequencia lógica. As frases estão "soltas" e o texto vai e volta,
abordando problemas gerais, depois se focando na UFTM para então
voltar a questões gerais. É preciso organizar isso, por exemplo,
começando com o que há de geral sobre o problema do lixo, depois
falando em soluções gerais para este e só então partindo para o
enfoque da UFTM".

De acordo com Koch e Elias (2017), ao produzir um texto, é necessário a eleição de um assunto ou tema, "aquilo de que se vai tratar", e a esse tema, por meio de uma relação de encadeamento e sequenciação, vai se acrescentando as informações necessárias para a contextualização, problematização e desenvolvimento do tema. No caso acima, se fizermos o exercício de perguntar do 
que fala o texto ou qual o seu objeto de discurso, teremos dificuldades para responder.

A referenciação difusa ao objeto ocorre porque, conforme anotado na intervenção docente, apresenta um problema que é muito comum na escrita de alunos de cursos de graduação: a dificuldade para identificar, delimitar e desenvolver um tema. $O$ trecho acima inicia com a seguinte afirmação: Este trabalho teve como temática a importância da separação do lixo, da conscientização dos discentes e docentes e da correta destinação do lixo que é produzido na UFTM diariamente. Se fossemos separar em blocos de palavras chaves, temos: importância da separação do lixo; conscientização dos discentes e docentes; correta destinação do lixo. Estes blocos sem dúvida apresentam relação semântica e mesmo pragmática, entretanto exigem, se abordados em um mesmo texto, a construção de uma argumentação que explicite essa relação.

A não identificação, o não saber realizar a delimitação e, consequentemente, visualizar o objeto da qual se escreve, afeta a progressão temática do texto. No fragmento acima, esse problema aparece no parágrafo subsequente: "Com o avanço da urbanização dos países em desenvolvimento, fato no qual o Brasil se insere, é possível verificar o incessante aumento da produção de lixo. Segundo Tinoco e Kraemer (2011, p. 89), a gestão ambiental é "o sistema que inclui a estrutura organizacional, atividades de planejamento, responsabilidades, práticas, procedimentos, processos e recursos para desenvolver, implementar, atingir, analisar criticamente e manter a política ambiental". Neste caso, novos temas foram inseridos, tais como avanço da urbanização e desenvolvimento, aumento da produção de lixo; gestão ambiental, dentre outros. Os três temas anunciados nos objetivos do projeto, de fato, não são retomados, desdobrados. A dificuldade de delimitação do tema aparece ainda quando a discussão muda de um espaço específico, a UFTM, para um espaço amplo, como "o Brasil" e "os países em desenvolvimento", sem o estabelecimento da relação entre o que acontece na universidade, em termos de reciclagem, consciência de preservação ambiental e o que acontece no Brasil e em países em desenvolvimento.

Ter um objeto, um referente permite o estabelecimento de uma espécie de acordo sobre a qual se organiza a produção de sentidos. Nesse sentido, a 
necessidade e o saber delimitar é assumir que não se pode dizer tudo ou qualquer coisa sobre um determinado tema. O que dizer está fortemente relacionado ao objetivo, ao posicionamento assumido e, principalmente, ao que se pretende dizer ao leitor. Ou, no caso em análise, por se tratar de um projeto, ao que se pretende pesquisar. Em suma, a dificuldade para definir o objeto de que fala afeta 0 estabelecimento da unidade temática, a progressão do texto e, principalmente, 0 propósito comunicativo, uma vez que, ao ler o trecho acima, fica para o leitor a pergunta: do que falam eles?

\section{O USO DO SENSO COMUM COMO ARGUMENTO}

A ideia de senso comum diz respeito ao conhecimento proveniente das vivências e observações do mundo realizadas por um determinado grupo de pessoas. De acordo com Cotrim (2002), o "[...] vasto conjunto de concepções geralmente aceitas como verdadeiras em determinado meio social recebe o nome de senso comum" (COTRIM, 2002, p.46). Neste sentido, principalmente na elaboração de uma proposta de pesquisa, se usado como estratégia argumentativa, o senso comum pode ser um ponto de partida, de problematização do que se pretende estudar. Entretanto, na maioria das versões iniciais dos projetos, o senso comum foi usado como embasamento para afirmações, como mostra o exemplo abaixo, cujo tema se relacionava às motivações dos licenciandos para escolherem a área de Ciências Biológicas; também foi usado para as dúvidas que tinham a respeito da escolha dessa área. No fragmento a seguir, há ausência de referências que embasem as afirmações, bem como o uso de termos "chavões" como, "A desvalorização contínua", "Tão importante carreira" "inversão de valores" e “...é uma profissão que tem a responsabilidade de educar, ensinar e formar cidadãos".

\footnotetext{
Texto dos alunos: "A desvalorização contínua do professor está relacionada não apenas à remuneração inferior do ideal, mas também à falta de reconhecimento da atividade docente o que mostra a inversão de valores existente, que desestimulam novas pessoas a seguir esta tão importante carreira, levando em consideração que é uma profissão que tem a responsabilidade de educar, ensinar e formar cidadãos."
} 
Intervenção do docente: Quais valores estão invertidos? Existente em que contexto? É importante que vocês tenham um embasamento sobre o tema, conseguido a partir de dados que o comprovem, ao invés de simplesmente apresentar uma alegação sem dados.

Uma alegação sobre as pessoas estarem desestimuladas a seguirem a carreira docente teria que ser amparada por dados que a comprovassem. Por exemplo, o déficit de professores nas escolas está aumentando ou diminuindo? E os números de ingressantes e formandos nos cursos de licenciatura? Ou ainda, qual a proporção de formandos em licenciatura que realmente ingressa na carreira docente? De fato, neste fragmento os alunos repetem um conjunto de discursos que estão disseminados em nossa sociedade, em diferentes contextos (midiático, acadêmico, político). A desvalorização do professor, a baixa remuneração, a falta de reconhecimento da atividade são temas científicos e popularizados. Nesse sentido, os temas são apresentados a partir da perceptiva do discurso das representações sociais e as suas formas textuais aparecem nessa escrita, principalmente nos seguintes trechos: "esta tão importante carreira" e "tem a responsabilidade de educar, ensinar e formar cidadãos”.

\section{A ESCRITA COMO BLOCO SEM MOVIMENTO}

A produção de um texto escrito exige de quem escreve a compreensão de que o seu leitor compreenderá o objetivo da escrita se o tecido textual mostrar caminhos, pistas para a leitura. Isso envolve um saber lidar com as afirmações feitas e, principalmente, compreender o quanto dessa afirmação precisa ser desdobrada, explicada para que o leitor compreenda o que está sendo dito.

Nas produções analisadas, foram observadas várias características da redação dos projetos que dificultam a compreensão. Entre estas características, destacam-se o abuso no uso de formas típicas da comunicação oral, a falta de articulação entre orações e frases e o uso de terminologia inadequada ou incorreta. Por exemplo, o trecho abaixo foi escrito no último parágrafo da introdução do projeto sobre "Abordagem de práticas alimentares saudáveis e sustentáveis nas escolas estaduais urbanas e rurais de Uberaba". 
Texto dos alunos: "Em conformidade a essas informações, esse projeto visa avaliar o direito à alimentação e, a conformidade e qualidade desta com a alimentação planejada pelos nutricionistas da Secretaria do Estado e Educação disponibilizada em cardápios específicos em seu site (SEE-MG, 2016)".

Intervenção da docente: "O que querem dizer com avaliar o direito à alimentação? Normalmente quando avaliamos algo queremos verificar se é bom ou ruim, adequado ou inadequado."

A docente aponta o problema no texto, mas o faz na forma de um questionamento, a fim de que o grupo avalie criticamente sua própria escrita e busque reformulá-la de uma maneira que melhor reflitam e esclareçam os objetivos do projeto. Entretanto, após essa intervenção, a opção do grupo foi deixar o texto da seguinte forma:

Texto dos alunos: "Em conformidade a essas informações, esse projeto visa verificar a conformidade e qualidade da alimentação realizada nas escolas com a alimentação planejada pelos nutricionistas da Secretaria do Estado e Educação disponibilizada em cardápios específicos em seu site (SEE-MG, 2016).

Intervenção da docente: Da versão anterior para esta vocês somente retiraram o trecho ".. esse projeto visa avaliar o direito à alimentação".

Cabe destacar que, no caso em análise, a retirada pode ser vista também como consequência da percepção do grupo de que não havia necessidade da expressão "avaliar o direito à alimentação", pois avaliar, neste caso, significaria estabelecer juízo sobre este direito. Os alunos conseguiram perceber que a falta de clareza na redação inicial desse trecho levava o leitor a ter uma ideia diferente daquela pretendida. $\mathrm{O}$ objetivo pretendido era verificar a qualidade da alimentação servida nas escolas. Para tanto, pretendiam analisar os cardápios semanais para avaliarem a qualidade nutricional destes e a correspondência deste com a proposta pela SEE-MG. Da maneira como escreveram inicialmente, ficava a ideia de que se propunham a avaliar um direito, no caso, à alimentação, garantida pela Declaração Universal dos Direitos Humanos (ONU, 2009. Art. XXV.1).

Ainda com relação ao mesmo projeto citado anteriormente: 
Texto dos alunos: Também será realizado uma comparação da quantidade de resíduo gerado por cada estabelecimento, de acordo com os produtos oferecidos por estes.

Intervenção da docente: Esta frase descreve um objetivo (o que será feito) e não uma metodologia (como será feito).

Nesta intervenção a docente busca mostrar para o grupo que esta frase escrita na seção de metodologia mais se parece com objetivo e por isso era necessária a reescrita para que fosse claramente explicado como iriam fazer aquilo que haviam se disponibilizado. No entanto, na versão seguinte o grupo simplesmente removeu a frase. O grupo não tentou realmente solucionar a questão, optando por apenas retirar o trecho apontado como problemático. Esta estratégia de "fuga" foi observada com certa frequência durante a produção dos projetos: diante de um questionamento da docente sobre determinado trecho do texto, os alunos não buscam re-analisar e re-escrever (ou mesmo defender) o texto por eles produzido, mas apenas removem o trecho questionado. Esta prática interdita a construção de uma compreensão de que a escrita deve ser reescrita para se chegar com clareza ao projeto de dizer.

\section{O USO DO PLÁGIO COMO POSSIBILIDADES DE ESCRITA}

Comumente, o plágio é definido como o ato de copiar partes ou a íntegra de obras, livros, músicas e trabalhos escritos por outro autor. O plágio entre ingressantes nos cursos universitários é comum, pois muitas vezes eles desconhecem que esta prática seja inadequada, em parte porque ainda persiste no ensino básico a compreensão de que fazer pesquisa é o mesmo que copiar partes de livros (KROKOSCZ, 2012). Ou seja, nessa fase de escolarização é comum o aluno entregar, como pesquisa realizada, a cópia de partes (ou mesmo da íntegra) de textos produzidos por outros autores.

O plágio, a cópia literal, foi identificada nas primeiras versões de alguns dos projetos, principalmente como cópias de frases e parágrafos de textos que foram usados como embasamento teórico. O trecho abaixo mostra a intervenção da docente em trechos da introdução do projeto sobre "Os impactos ambientais 
gerados pelo descarte inadequado do óleo de cozinha" em que o grupo fez cópia literal de um artigo publicado na internet.

Trecho Do Projeto: O despejo de forma descontrolada de óleos residuais de fritura em pias e vasos sanitários, ou diretamente nas águas, acarreta uma série de danos ambientais, como o entupimento dos canos dos sistemas de esgoto e o encarecimento dos processos das estações de tratamento, além de acarretar a poluição do meio aquático (CASTELLANELLI, 2008) (REQUE; KUNKEL, 2010).

Trecho Do Artigo Publicado Na Internet: "O despejo de forma descontrolada de óleos residuais de fritura, em pias e vasos sanitários, ou lançados diretamente nas águas, acarreta uma série de danos ambientais como o entupimento dos canos dos sistemas de esgoto e o encarecimento dos processos das Estações de Tratamento, além de acarretar a poluição do meio aquático" (CASTELLANELLI, 2008). (REQUE; KUNKEL, 2010, p. 51).

Intervenção da docente: Todo este trecho destacado é cópia dos autores citados entre parênteses. Não se pode simplesmente copiar o que o outro disse, mesmo que vocês tenham citado os autores.

Nesta intervenção a docente mostra que mesmo os autores sendo citados não é correto a transcrição na íntegra do texto por eles escrito. A docente retomou a explicação sobre o que significa plágio e percebeu que o grupo havia entendido que se fossem citados os autores já havia permissão para o uso livre do que havia sido dito no artigo. Não houve a intencionalidade nesta ação do grupo e sim uma inabilidade com os requisitos próprios da escrita científica.

Krokoscz (2012) afirma que o avanço tecnológico facilita o copia e cola por universitários, uma vez que há aumento da aprendizagem virtual. Acreditamos também que o grande número de publicações de artigos, teses, dissertações e monografias facilita o plágio. Ou seja, um aluno que acaba de chegar à universidade, acostumado a compreensão de que pesquisar é o mesmo que copiar, comete o plágio na maioria das vezes porque ainda não tem clareza de que, de fato, pesquisar, escrever na universidade não é isso. O trecho abaixo mostra outra intervenção docente em trechos da introdução do projeto sobre "Universitários com dúvidas a respeito do curso que escolheram". 
Texto dos alunos: A evasão de um curso pode ser motivada por diversos fatores. Na área das licenciaturas, a motivação vem do desinteresse pela docência na educação básica, pelos salários abaixo da média, pelas condições precárias de trabalho, pelo diploma muitas vezes desvalorizado e também pela falta de informações a respeito dos cursos.

Intervenção docente: De onde vem as informações desta frase? Referencie-as.

O tema da afirmação escrita pelos alunos é normalmente repetido não só por eles, mas também, em parte, por docentes, o que torna esse tema comum em diferentes aulas. Por ser uma abordagem oralizada, o que comumente não vem acompanhada da exigência de citar referência, o aluno passa a acreditar que a mesma prática pode se repetir na escrita. No entanto, quando se trata de uma escrita acadêmica, é necessário mostrar a fonte e, caso a intenção seja parafraseála, esta deve ser feita adequadamente. A formação docente, o incentivo à carreira na área de Ciências Biológicas tem sido tema de estudo nos programas institucionais de bolsas de iniciação à docência (PIBID) como o da UFTM, e há publicações que discutem esse tema (PEREIRA, 2006; PAREDES E GUIMARÃES, 2012). Desta forma, a repetição, neste momento, não é uma simples tentativa de se apropriar da voz alheia, do discurso do outro. Entre esses alunos, o que explica tal repetição é a imaturidade, a pouca ousadia de serem autores dos seus próprios textos e não uma intencionalidade nesta adesão ao discurso do outro.

$\mathrm{Na}$ intervenção abaixo, ainda no projeto "Os impactos ambientais gerados pelo descarte inadequado do óleo de cozinha", a docente aponta um caso de plágio no texto da introdução. Apresenta considerações gerais, procurando levar o grupo a melhor desenvolver esta parte. Embora a pesquisa bibliográfica mais aprofundada seja sugerida como solução para os problemas de plágio apresentados, não são oferecidas sugestões de bibliografia nem de direcionamentos para a busca desta. Sugestões deste tipo iriam justamente evitar que o grupo fizesse a sua própria pesquisa. Também não são indicados explicitamente todos os trechos contendo plágios e paráfrases, uma vez que se pretendia que a equipe buscasse ativamente identificá-los. 
Texto dos alunos: A pequena solubilidade dos óleos vegetais na água constitui um fator negativo no que se refere à sua degradação em unidades de tratamento de despejos por processos biológicos (PASQUALETTO \& BARBOSA, 2008).

Intervenção da docente: No entanto houve o problema com algumas frases da introdução terem sido produzidas por meio de cópias, prática que, é claro, não é aceitável. Evitar esta prática exige pesquisa aprofundada e, sobretudo, diversificada sobre o tema abordado.

Neste recorte da introdução do projeto citado acima houve a prática do plágio. Os alunos transcreveram na íntegra uma cópia do trabalho publicado na internet. Havia nesta mesma introdução trechos em que também transcreviam na íntegra partes do mesmo texto somente com uma reorganização daquilo que já havia sido publicado sobre o tema.

O plágio neste grupo não foi percebido pela docente na primeira versão do texto e sim nas seguintes, quando o grupo entregou também a redação da metodologia. Neste momento, ficou perceptível que a qualidade inicial da redação da introdução não foi repetida na escrita da metodologia. Aliás, este é justamente uma das características que indicam plágio praticado por alunos iniciantes: a diferença entre a escrita própria e a escrita plagiada, que produz inconsistências resultando numa "colcha de retalhos" de diferentes estilos de escrita.

Após a detecção da prática de plágio na escrita do grupo, a docente fez a intervenção citada anteriormente e se reuniu presencialmente com os alunos para entender o motivo de terem realizado o plágio e novamente explicar sobre esta prática. A docente solicitou nova pesquisa e leitura sobre o mesmo tema. O grupo não se animou em fazer nova pesquisa mas se comprometeu a fazer a (re)leitura dos textos pesquisados anteriormente. Na versão seguinte do projeto foi possível perceber que o grupo conseguiu ter um pouco mais de segurança para começarem a escrever sem copiar, apresentaram um texto bem simples mas de autoria própria.

O trecho a seguir mostra mais um exemplo de plágio nos textos iniciais do projeto "Os impactos ambientais gerados pelo descarte inadequado do óleo de cozinha". 
Texto dos alunos: A escassez de recursos naturais, juntamente com os problemas relacionados à disposição inadequada dos resíduos no meio ambiente, foi aos poucos convencendo o homem da necessidade de se realizar a reciclagem.

Intervenção do docente: Esta frase é uma cópia na íntegra do artigo: "Coleta seletiva de lixo domiciliar - estudos de caso". (RIBEIRO, F.T e do CARMO LIMA, S., 2000).

Sobre este trecho, ressalta-se que o convencimento "do homem" a respeito da necessidade de reciclar está longe de ser um consenso entre os pesquisadores do tema. Atesta essa falta de consenso o grande número de estudos sobre as dificuldades encontradas para conscientizar as pessoas e sobre a importância de se incluir discussões sobre meio ambiente nos currículos escolares (ZUBEN, 1998, BRITTO, 2000; GUIMARÃES 2005; entre outros). Ou como destaca Fonseca (2013), há um crescente estímulo com relação aos cuidados com o meio ambiente, mas na maioria das vezes não se sabe exatamente o que se fazer para alcançar este objetivo. Desta forma, o senso comum expresso no trecho do texto não reflete sequer um "conhecimento proveniente das vivências e observações do mundo realizadas" pela sociedade, ou por um grupo majoritário, mas provavelmente reflete apenas o senso comum dos próprios membros do grupo de autores do projeto.

\section{A ESCRITA DA METODOLOGIA DOS PROJETOS}

Abaixo são transcritos alguns exemplos de intervenções realizadas nos textos sobre a metodologia dos projetos. O trecho a seguir foi retirado do projeto "Os impactos ambientais gerados pelo descarte inadequado do óleo de cozinha".

Texto dos alunos: O método de pesquisa que iremos utilizar será o misto. Esse tipo de pesquisa é mais "prática" no sentido de que nós estamos livres para usar todos os métodos possíveis para abordar o tema a ser pesquisado".

Intervenção docente: Não entendi o que quiseram dizer com "estar livres para usar todos os métodos possíveis". Pesquisa exige planejamento; não há espaço para improvisos". 
Neste trecho do texto da primeira versão da metodologia, o grupo não deixa claro o que é um método misto de pesquisa e exibe desconhecimento sobre os critérios para a escrita dessa etapa de um projeto. Na versão seguinte, corrigem o trecho e explicam que farão uma análise documental no restaurante, estabelecimento em que irão buscar os dados da pesquisa.

Texto dos alunos: O método de pesquisa que iremos utilizar na parte qualitativa é a análise documental em forma de questionário, que é uma importante fonte de dados, e o estudo de caso, em que iremos analisar as formas utilizadas para o descarte do óleo nos estabelecimentos em questão. Intervenção docente: Os questionários que vocês irão produzir não são documentos dos estabelecimentos, portanto não faz sentido falar em análise documental aqui, portanto retirem as referências a este método.

Novamente foi necessário intervir, pontuando que análise documental é a análise de documentos produzidos pelos entes analisados (no caso os restaurantes), mas o que os alunos pretendiam era utilizar questionários para levantar dados a respeito de uma questão sobre a qual se sabe pouco (as formas utilizadas para o descarte do óleo nos estabelecimentos em questão), não havendo portanto pesquisa documental. Por outro lado, em sua intervenção a docente se abstém de simplesmente indicar em qual modalidade de pesquisa o uso de questionários se encaixa, de forma que caberia aos alunos buscarem este conhecimento. O grupo retirou a menção a análise documental e manteve o uso do questionário porém sem explicitar qual era a modalidade de pesquisa que utilizariam.

Abaixo é transcrito um exemplo de intervenção realizada no projeto "Universitários com dúvidas a respeito do curso que escolheram". Os discentes propõem um levantamento, com seu público-alvo, para a realização de uma ação na escola, mas não especificam qual seria esta e nem o objetivo para que esta ação seja realizada. 
Texto dos alunos: A partir desse levantamento com o público alvo será realizado o plano de ação com os discentes do ICENE - UFTM."

Intervenção docente: Qual a ação proposta a partir deste levantamento? Ação para que?

Neste trecho do texto, há excessiva sumarização do conteúdo a ser dito, inviabilizando o entendimento do leitor a respeito de qual ação estava sendo proposta e qual objetivo se esperava alcançar. As perguntas visaram salientar as lacunas, o como o texto escrito demanda detalhamentos para o que leitor tenha clareza do que está sendo dito. Neste momento inicial faltava aos alunos a compreensão de que o texto é de fato um tecido constituído por elementos linguísticos selecionados e ordenados de modo que possibilite a aquele que lê interagir com os conteúdos semânticos e, consequentemente, com os sentidos propostos e que as lacunas apontadas não permitiam essa interação. O mesmo grupo, na versão final do projeto, mostrou ter compreendido estas necessidades do texto, tendo produzido então uma escrita que aponta para um projeto enunciativo mais claro.

Texto dos alunos: Visto isso, este projeto tem como objetivo buscar saber se 0 ingressante no curso de licenciatura em Ciências Biológicas tem conhecimento sobre o curso que está adentrando e sobre as suas futuras possibilidades de atuação, além de esclarecer alguns pontos sobre as grandes áreas de atuação do Licenciado em Ciências Biológicas.

Intervenção docente: Houve bastante dificuldade em focar o projeto ao longo de seu desenvolvimento, em parte devido justamente a complexidade do tema, mas me parece que a versão final do trabalho superou estas dificuldades.

Nesta intervenção, o objetivo foi ressaltar a superação da dificuldade apontada desde o início da escrita do projeto, ou seja, a de que a complexidade do tema requeria muita pesquisa e leitura para a compreensão e produção de uma escrita acadêmica adequada. Este projeto buscou investigar os motivos que levam os ingressantes a desistirem do curso universitário escolhido, mas inicialmente não estava claro, inclusive para os autores, qual era o objetivo do projeto. A docente aponta que o tema é bastante complexo, pois o desconhecimento, as decepções e a evasão em um curso universitário tem causas variadas e, frequentemente, 
multifatoriais, sendo preciso cuidado ao tentar obter dados a respeito junto aos discentes, não apenas para garantir que estes realmente representem o fenômeno estudado (e não apenas, por exemplo, as opiniões dos membros do grupo, ou de autores de outros trabalhos, a respeito) mas também para evitar causar danos aos sujeitos de pesquisa.

Para o desenvolvimento da metodologia do projeto, esse grupo inicialmente havia proposto analisar questões que fugiam as reais possibilidades de tempo, recursos e conhecimento disponíveis a eles, pois englobavam inclusive diagnósticos médicos, ou seja, temas e possíveis laudos médicos que não estariam dentro da nossa competência avaliá-los. Inicialmente o grupo se propunha a conhecer o perfil dos alunos, mas esqueciam ou ignoravam que, para conhecer o perfil de alguém, é necessário levantar várias informações sobre a pessoa e para isso, seria necessária uma equipe multidisciplinar de profissionais para a realização deste levantamento.

Ao longo do semestre esse grupo foi percebendo a necessidade de adequar seus objetivos às possibilidades reais de execução e tempo hábil para a realização do projeto e discussão dos resultados obtidos com ele. Por fim, o grupo sorteou discentes do primeiro, segundo e terceiro períodos do curso de licenciatura em Ciências Biológicas da UFTM, para responderem a um questionário, elaborado pelo grupo, e posteriormente participarem de uma palestra em que seriam exibidos e discutidos os resultados do projeto. O questionário proposto pelos alunos teve como objetivo coletar e permitir a análise sobre a escolha, o grau de conhecimento e as dúvidas a respeito do curso citado, além das impressões que os alunos obtiveram durante os períodos mencionados anteriormente. Após a aplicação do questionário, esse mesmo grupo procurou alguns profissionais da área para realizarem uma entrevista para conhecer a trajetória deles e, com isso, conseguirem analisar adequadamente os resultados do projeto. Com esta organização final, foi possível perceber que o grupo conseguiu focar mais nos objetivos do projeto, sem divagarem sobre questões que fugiriam das reais possibilidades de coleta e análise dos dados obtidos.

Outra questão que exigiu da parte do grupo compreensão e adequação com relação à metodologia proposta foi sobre a realidade das escolas ou demais espaços nos quais as atividades de pesquisa seriam desenvolvidas. Em várias 
versões iniciais dos projetos, os grupos não definiam claramente o público-alvo nem levaram em consideração se teriam ou não a colaboração dos "atores" destes espaços. Ou seja, não consideram a possibilidade de que os possíveis pesquisados poderiam não aceitar responder a um questionário, participar de uma entrevista ou oficina.

Esse aprendizado da necessidade de considerar as possíveis (re)ações de um campo de pesquisa é importante. No caso da escola, trata-se de um campo de pesquisa em que diretores, docentes, alunos estão habituados a responderem questionários ou participarem de projetos de pesquisas propostos pela universidade. Mesmo assim pode haver resistências. Além disso, nos projetos dos grupos, escola e universidade não foram os únicos espaços escolhidos para desenvolvimento dos projetos. Estabelecimentos como restaurantes e mercados também foram postos como campo de pesquisa. É menos comum que nestes últimos espaços sejam aplicados questionários ou entrevistas com cunho investigativo na educação, sendo assim essencial que os atores deste espaço fossem bem definidos e previamente consultados sobre a participação ou não deles nestas metodologias. Como mostram os trechos abaixo:

Texto do aluno: Será aplicado um questionário nos estabelecimentos com a finalidade de averiguar o nível de conhecimento, em relação ao descarte do óleo de cozinha.

Intervenção docente: Não há definição do público-alvo, nem sobre quais estabelecimentos serão pesquisados.

Texto do aluno: "Será aplicado um questionário (anexo A) para os funcionários e proprietários dos estabelecimentos, com a finalidade de averiguar o nível de conhecimento neste em relação ao descarte do óleo de cozinha.

Intervenção docente: Nesta versão o grupo começa a definir o públicoalvo mas ainda não há clareza sobre qual estabelecimento será realizada a pesquisa.

No primeiro trecho citado, não há definição do público-alvo nem informação sobre quais estabelecimentos serão pesquisados ou se este público foi previamente consultado. Esta intervenção docente objetivou mostrar aos discentes que é 
necessário ter clareza na escrita para que seja possível entender os caminhos que o projeto trilhará para alcançar os objetivos propostos.

$\mathrm{Na}$ versão seguinte, tais questões começaram a ser resolvidas com a definição do público-alvo, porém ainda sem a clara definição sobre quais estabelecimentos seriam pesquisados, se restaurantes, lanchonetes ou bares, ou sobre a autorização ou não para estes "atores" participarem. Desde o início, o grupo havia proposto o restaurante como o espaço para realizar a pesquisa. No entanto, não escreviam claramente sobre isso, nem definiam quais "atores" deste local seriam consultados. Somente na versão final deste grupo estas lacunas foram preenchidas indicando-se quem seriam os "atores" e o local a ser pesquisado.

Essas imprecisões apontam para diferentes possibilidades: não compreensão do que deve conter uma metodologia de pesquisa; dificuldade para visualizar as lacunas da própria escrita; ou mesmo mera postergação para realização do que está sendo solicitado.

\section{CONSIDERAÇÕES FINAIS}

Como explicado na introdução, a disciplina EDPI é cursada no primeiro período do curso de Licenciatura em Ciências Biológicas. Desta forma, as características dos textos iniciais produzidos pelos alunos e aqui discutidos refletem, em alguma medida, a pouca (as vezes quase inexistente) e frágil atividade de leitura e escrita científica dos acadêmicos antes de chegarem ao ensino superior (GERMANI, 2017).

$\mathrm{Na}$ maioria dos projetos escritos e discutidos neste artigo percebe-se uma tendência para a escrita de textos iniciais com caráter superficial e generalizante, nos quais problemas amplos e complexos são abordados a partir de senso comum e acúmulo de informações pouco estruturadas, sem foco numa questão específica nem construção de um fluxo lógico e coerente de raciocínio. Essas deficiências podem estar relacionadas ao fato de serem alunos de primeiro período, sem orientação (nem contato) anterior sobre a forma de escrita acadêmica, mas também revelam deficiências mais gerais quanto à capacidade de redigir textos mais complexos. 
Apesar dos padrões de escrita observados inicialmente, notou-se entre os alunos uma sensível mudança com relação as competências essenciais para a escrita acadêmica até o final da disciplina. Os alunos foram capazes de incorporar a sua escrita, linguagens, formas, estrutura e lógicas próprias de textos de projetos científicos.

Para a maioria dos grupos, a fundamentação teórica ficou mais consistente, tanto no que diz respeito a qualidade quanto à quantidade e relevância das fontes citadas. Também foram notadas de forma bastante incisiva a produção de textos com maior clareza e organização lógica, indicando que os alunos adquiriram competências e habilidades relacionadas à produção de textos com estas características.

De modo geral, a parte metodológica dos projetos também ganhou robustez e viabilidade ao longo das oficinas de escrita. Robustez aqui se refere ao fato de terem sido propostas metodologias que poderiam realmente alcançar os objetivos e responder as questões propostas pelos trabalhos; enquanto viabilidade se refere à possibilidade de implementar a metodologia proposta no tempo disponível (o próximo semestre letivo) e usando os recursos materiais e humanos disponíveis. Esta mudança merece destaque, uma vez que as propostas iniciais dos projetos não apresentavam preocupações em relação a estes pontos.

Similar à dificuldade de considerar o tempo e o espaço em que os projetos seriam desenvolvidos, muitas versões iniciais também não definiam claramente o público-alvo nem levaram em consideração se este público aceitaria responder a um questionário ou participar de uma entrevista ou oficina. Ao longo das oficinas de escrita todas as equipes foram aos poucos equacionando estas questões metodológicas, entendendo por exemplo a importância da escolha cuidadosa dos estabelecimentos participantes, a fim de conseguir parceiros que participem ativamente do projeto.

Em suma, a oportunidade de escrita e reescrita de textos proporcionada pela EDP I logo no início da vida acadêmica foi importante, pois possibilitou aos discentes um autodiagnóstico a respeito de suas fragilidades ou potencialidades na produção de textos. É preciso ressaltar que, além da necessidade de disciplinas como esta que levem à compreensão de que a escrita envolve constante trabalho e retrabalho, 
é importante que os alunos compreendam também que a leitura deve ser uma prática rotineira para aqueles que estão na universidade. A leitura é a atividade parceira da escrita. Esta não se realiza sem a leitura. Ler não é o ato de identificar e copiar o que outro autor produziu sobre um determinado tema. É fundamental que iniciantes na universidade compreendam que ler é o ato de compreender o que o outro produziu sobre um determinado tema e, a partir disso, passa-se a produção de novas leituras e compreensões por meio da escrita.

\section{REFERÊNCIAS}

BEZERRA, G. O; A; FERREIRA, L. G. Experiência de Ensinar e Aprender no PIBID: O Ensino de Ciências e da Biologia. Experiências em Ensino de Ciências V.14, no.1, 2019.

AMBROSETTI, N.B; CALIL, A. M; ANDRE, M.E.D.A de; ALMEIDA, P.C.A. O PIBID e a aproximação entre universidade e escola: implicações na formação profissional dos professores. Atos de Pesquisa em Educação. Blumenau, v.10, n.2, p.369-392, 2015.

BARZOTTO, V. H. Leitura, Escrita e Relação com o conhecimento. Campinas: Mercado de Letras, 2016.

BARZOTTO, V. H.; BARBOSA, M. V. (Orgs.) Leitura, Escrita e pesquisa em Letras: análise do discurso de textos acadêmicos. Campinas: Mercado de Letras, 2014.

BERNHEIM, C. T.; CHAUÍ, M. S. Desafios da Universidade na Sociedade do Conhecimento: cinco anos depois da conferência mundial sobre educação superior. Brasília: UNESCO, 2008. Disponível em: <http://unesdoc.unesco.org/images/0013/001344/134422por.pdf>. Acesso em: 28/07/2020.

BRASIL, Ministério da Educação. Base Nacional Comum Curricular - BNCC, versão aprovada pelo CNE. Brasília, DF, 2017. Disponível em: http://basenacionalcomum.mec.gov.br/. Acesso em: 08 mai. 2020.

BRITTO, C. Educação e Gestão Ambiental. Salvador: Ministério do Meio Ambiente, 2000.

CASTELLANELLI, Carlo Alessandro. Feasibility study of biodisek production obtained through the used frying oil in Santa Maria city. 2008. 112 f. Dissertação 
(Mestrado em Engenharia de Produção) - Universidade Federal de Santa Maria, Santa Maria, 2008.

COTRIM. Gilberto. Fundamentos da filosofia: história e grandes temas.15. ed.

São Paulo: Saraiva, 2002.

BUNGE, Mario. Causality and modern science. New York: Dover, 1979. Epistemologia: curso de especialização. São Paulo: Universidade de São Paulo: 1980a.

FOUCAULT, Michel. Verdade e poder. In: FOUCAULT, Michel. Microfísica do poder. 11. ed. Rio de Janeiro. Edições Graal, 1993a. p. 1-14.

FONSECA, Lúcia Helena Fonseca. Reciclagem: o primeiro passo para a preservação ambiental. Revista Científica Semana Acadêmica. Fortaleza, ano MMXIII, №. 000036, 10/07/2013.

GERALDI, J. W. Linguagem e ensino: exercícios de militância e ensino. Campinas, SP: Mercado de Letras, 1996.

GERMANI, M.M; Parisotto, A.L.V. A escrita no ensino superior: uma análise desenvolvida com alunos do quinto ano do curso de Direito. Dissertação de mestrado. Universidade Estadual Paulista (UNESP), 2017.

GUIMARÃES, M. A dimensão ambiental na educação. Campinas-SP: Papirus, 2005.

KOCH, I. V; ELIAS, V. M. Escrever e argumentar. São Paulo: Editora Contexto, 2017.

KROKOSCZ, Marcelo. Autoria e Plágio: um guia para estudantes, professores, pesquisadores e editores. São Paulo: Editora Atlas, 2012.

LUNA, S.V. de. Planejamento de pesquisa: uma introdução. São Paulo: Educ, 1997. ISBN 8528301036.

MOYSÉS, M. A. A.; GERALDI, J. W.; COLLARES, C. A. L. As aventuras do conhecer: da transmissão à interlocução. Revista Educação \& Sociedade, ano XXIII, n. 78, Abril/2002.

ONU, Organização das Nações Unidas. Declaração Universal dos Direitos Humanos. 2009. Disponível em: <https://www.onu.org.br/img/2014/09/DUDH.pdf>. Acesso em: 15 maio 2018.

PAREDES, G. G. O. GUIMARÃES, O. M. Compreensões e significados sobre o PIBID para a melhoria da formação de professores de Biologia e Química. Química Nova na Escola, n. 4, vol. 34, p. 266-277, 2012. 
PASQUALETTO, A.; BARBOSA, G. N. Aproveitamento do óleo residual de fritura na produção de biodiesel. In. XXXI Congresso Interamericano AIDIS. Santiago, Chile, 12 a 15 de outubro, 2008, 8p.

PEREIRA, Antonio. A educação não formal e educação social na ordem do dia: entre conflitos e possibilidades educativas. In: Revista Metáfora Educacional (ISSN 1809-2705) -versão on-line, n.15 (jul. -dez. 2013),Feira de Santana -Bahia (Brasil), dez./2013. p. 129-148.

PEREIRA, J. E. D. Formação de professores - pesquisa, representações e poder. 2. ed. Autêntica, Belo Horizonte, 2006.

REQUE, P.T.; KUNKEL, N. Quantificação do óleo residual de fritura gerado no município de Santa Maria-RS. Disciplinarum Scientia Naturais e Tecnológicas, v. 11 , n. 1, p. 50-63, 2010.

RIBEIRO, T. F.; do Carmo LIMA, S. Coleta seletiva de lixo domiciliar: estudo de casos. Uberlândia: Caminhos de Geografia, v. 2, n. 2, p. 51, 2000.

SEE-MG, Secretaria de Estado de Educação de Minas Gerais. Alimentação Escolar. 2016. Disponível em: $<$ https://www.educacao.mg.gov.br/parceiro/alimentacao-escolar-cardapios>. Acesso em: 17 maio 2018.

TINOCO, Eduardo P., KRAEMER, Maria Pereira. Contabilidade e gestão ambiental. 3. ed. São Paulo: Atlas, 2011.

ZUBEN, F. V. Meio Ambiente, Cidadania e Educação. Departamento de Multimeios. Unicamp. Tetra Pak Ltda. 1998.

Recebido em: 05/08/2020

Aprovado em: 22/09/2021 